\title{
Study on the Semiactive Control and Optimal Layout of a Hydropower House Based on Magnetorheological Dampers
}

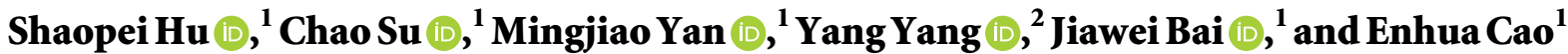 \\ ${ }^{1}$ College of Water Conservancy and Hydropower Engineering, Hohai University, Nanjing 210098, China \\ ${ }^{2}$ PowerChina KunMing Engineering Corporation Limited, KunMing 650051, China
}

Correspondence should be addressed to Chao Su; csu_hhu@126.com, Mingjiao Yan; ymjwing@qq.com, and Yang Yang; yangyhhu@foxmail.com

Received 11 December 2020; Revised 21 January 2021; Accepted 3 November 2021; Published 3 December 2021

Academic Editor: Hao Wang

Copyright ( $\odot 2021$ Shaopei Hu et al. This is an open access article distributed under the Creative Commons Attribution License, which permits unrestricted use, distribution, and reproduction in any medium, provided the original work is properly cited.

With the continuous development of hydropower stations, the capacities and the heads of hydro generator units are increasing, and the plant vibration problem is becoming more and more serious. A numerical simulation method for the vibration reduction control of magnetorheological (MR) dampers suitable for large-scale complex structures was proposed. The method is simple and easy to implement, and the semiactive control of the MR damper could be achieved by adjusting the current switch and size. On the basis of a numerical simulation, a mathematical model for the optimal layout of an MR damper device was established. The objective function was the vertical velocity and the vertical acceleration response of the generator floor. The results showed that the proposed semiactive control numerical simulation method could be applied to the vibration control of the hydropower plant structure, and the vertical velocity and vertical acceleration were reduced by $10.96 \%$ and $12.90 \%$, respectively, compared with those without structural vibration control. At the same time, the proposed optimized layout method was effective and feasible, and the damping effect of the MR damper could be effectively improved through the optimized layout.

\section{Introduction}

The vibration of hydropower generating units is a major issue related to the safe and stable operation of hydropower generating units. The vibration will not only consume part of the power, reduce the efficiency of the unit, and shorten the maintenance cycle and service life but also cause the entire plant structure and the water pipes to be forced to stop [1-3].

As a new type of intelligent vibration damping device, magnetorheological (MR) damper has the advantages of simple structure, a wide range of damping force, fast response (millisecond level), low energy consumption, and large output damping [4]. In recent years, scholars around the world have carried out a lot of research on the vibration damping control of MR dampers. Mohajer Rahbari et al. [5] used MR dampers to study the semiactive control of threeand eleven-layer shear wall structures, and they evaluated the performance of the conversion controllers. Zahrai and Salehi [6] selected nine- and twenty-story buildings and used
MR dampers to conduct semiactive control studies on the buildings. The results showed that the maximum acceleration of the structure was reduced by more than $21 \%$, so the use of semiactive control could greatly reduce the structural response. Ok et al. [7] used MR dampers to conduct semiactive control studies on cable-stayed bridges. The simulation results showed that the use of MR dampers significantly reduced the structural response of cable-stayed bridges. Bhaiya et al. [8] used a limited number of MR dampers to optimally control a ten-story building frame structure, and they studied the influence of the position of the MR dampers on the response. The semiactive control of the damper could effectively reduce the response of the frame structure. Abdeddaim et al. [9] used MR dampers to link two adjacent buildings on the top layers of two adjacent buildings, and this coupling strategy effectively reduced the vibration response of the structure. At present, MR dampers have achieved good vibration reduction effects in bridges, buildings, offshore platforms, and other constructions. 
However, they have not been used in the vibration reduction of the hydropower plant.

The process of reducing the dynamic response of the structure is called structural vibration control by applying a control system to the structure to make the structure resist the action of dynamic load [10]. In 1972, Yao [11] gave the notion of structural control, and since then, this field has emerged by leaps and bounds. To date, it is commendable to have adopted some control strategies. The displacement response of the bridge in earthquakes can be effectively reduced by employing the shape memory alloy (SMA) in the sliding-lead rubber bearing (LRB) system [12, 13]. During an earthquake, the temperature adjustment of the SMA in the pendulum friction bearing (FPB) system effectively alters its hysteresis energy dissipation capacity, thereby changing the control efficiency of the isolation system [14]. The new basic vibration isolator using sliding implant-magnetic bearing and sliding hydromagnetic isolators achieves better performance in earthquake/vibration isolation and mitigation $[15,16]$. The use of a hybrid controller can improve the comfort of the vehicle and the stability of the movement [17-19]. The application of damper control strategies to reduce the displacement response of buildings in earthquakes has been proven $[20,21]$. These strategies offer the prospect of developing applications, improving efficacy, and providing better acceptability. Among them, the semiactive control strategy combines the excellent control effect of active control and the advantages of simple and easy passive control, while overcoming the shortcomings of active control requires a large amount of energy supply and narrow tuning range of passive control. Therefore, semiactive control has a greater prospect for research and application development [22], and it has attracted more and more attention from scholars. Bathaei et al. [23] used two different fuzzy controllers to study the seismic vibration of an adaptive MR damper. This method could further reduce the maximum displacement, acceleration, and foundation shear force of a structure. Lee et al. [24] proposed a semiactive damping control strategy based on a neural network controller and an MR damper. Compared with passive control, the numerical simulation results showed that the proposed controller could significantly reduce floor acceleration, base shear, and angular displacement. Hazaveh et al. [25] used discrete wavelet transform (DWT), a linear quadratic regulator (LQR), and a limiting optimal control algorithm to determine the optimal control force. The semiactive control performance was evaluated by comparing the maximum displacement, the total shear force of the substrate, and the control energy. The damping effect of the MR damper depended on the size of the input current, the control method, and the arrangement of the MR damper. Kim and Lee [26] proposed a sensitivity evaluation algorithm to make the neurocontrol system compact and reduce the total training time without an emulator. At present, the theoretical researches on the damping control of MR damper require a certain simplification of the structure in the calculation. The analysis of structural control by instantaneous dynamics was used in ABAQUS simulation analysis, and the characteristics of material nonlinearity and geometric large deformation could also be considered.

Installing energy damping devices at optimal locations helps designers achieve the desired reduction of vibrations with minimum costs. At present, the commonly used methods for this problem are the "trial and error method" and the "exhaustive method." The former method generally obtains a local optimal solution, while the latter method is only suitable for systems with small spaces [27]. A more precise inspection of all feasible arrangements to find out which one would produce the expected structural reduction dynamic response turned out to be very time-consuming. Dealing with this problem, researchers have suggested different approaches. Singh and Moreschi [28] used a genetic algorithm to find the optimal position of an MR damper. Amini and Ghaderi [29] proposed an improved ant colony optimization algorithm to optimize the installation position of an MR damper. Agranovich and Ribakov [30] proposed a heuristic solution for the efficient placement of active dampers in seismically excited structures. Main and Krenk [31] presented the studies concerning the allocation and sizing of viscous dampers. Lewandowski [32] investigated the optimal distribution of viscous dampers by an objective function in the form of a sum of weighted, nondimensional modal damping ratios. Singh and Moreschi [33] obtained the optimal arrangement of dampers based on the gradient method. A genetic algorithm is a randomized search method derived from the evolution of biological evolution law, and it can automatically and gradually seek the optimal solution or approximate the optimal solution of the problem space [34].

In this paper, we realize the passive control and semiactive control of the magnetorheological damper by using two subroutines, URDFIL and DLOAD, based on the Bouc-Wen model. Then, a mathematical model for the optimization design of the plant layout of the MR damper was established, and the optimization objective function was selected to minimize the vertical velocity and acceleration response of the generator floor. Using a multiobjective genetic algorithm, the encoding methods, population initialization, crossover, and mutation adaption to the spatially optimized layout of the MR dampers were proposed to optimize the layout of the MR dampers. Finally, the different vibration damping control methods were used to evaluate the damping effect of the MR damper after the optimized arrangement.

\section{Magnetorheological Damper}

MR damper is currently the fastest research and development field for MR fluids. It is a new type of intelligent damping device that uses MR effects. MR damper is a damper made of MR fluid, and its structure is shown in Figure 1. It is composed of electrical control lines, piston rod, piston, orifice, and buffer accumulators. MR damper has a simple device, low energy consumption, fast response, large damping, and wide dynamic range. The damping force can be controlled by adjusting the current or voltage, so it can be well integrated with the control system. Even when the 


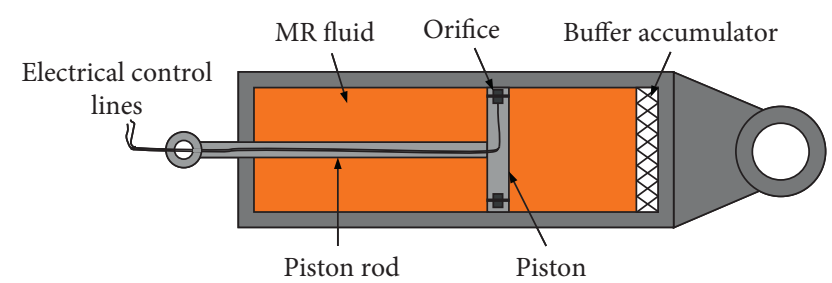

FIgURE 1: Schematic diagram of the magneto-rheological damper.

control system fails, it can also be used as a passive controller with strong reliability.

\section{Bouc-Wen Model}

Wen [35] proposed a simple mathematical hysteresis model, called the Bouc-Wen model in 1976. The model consisted of a hysteretic system, a spring and a damper in parallel, as shown in Figure 2. The Bouc-Wen model was universal and easy to be digital modeling. It could accurately reflect the nonlinear performance of the MR damper at a low speed and simulate the hysteretic characteristics of the MR damper. follows:

The damping force of the model can be expressed as

$$
\begin{aligned}
& F=c_{0} \dot{x}+k_{0}\left(x-x_{0}\right)+\alpha z, \\
& \dot{z}=-\gamma|\dot{x}| z|z|^{n-1}-\beta \dot{x}|z|^{n}+A \dot{x},
\end{aligned}
$$

where $F$ is the damping force of an MR shock absorber; $\alpha$ represents the model parameters related to the MR yield stress; $k_{0}$ is the spring stiffness; $c_{0}$ is the viscosity coefficient of the MR material after yielding; $x$ and $\dot{x}$ are the relative displacement and the relative velocity of the MR damper piston and cylinder, respectively; $z$ is the hysteresis displacement; $x_{0}$ is the initial deformation of the spring; and $A, \beta, \gamma$, and $n$ are constants that were determined by the structural characteristics of the MR damper.

The solution flow chart of the Bouc-Wen model is shown in Figure 3. This model contains eight unknown parameters. As shown in Figure $3, x$ is a sinusoidal displacement excitation signal $x=A \sin (2 \pi f t)$, where $A$ is the amplitude, $f$ is the frequency, and Partialz is a Simulink subsystem that was used to evaluate the hysteresis $\dot{z}$ in the model.

\section{Numerical Simulation Method}

The damping control of the MR damper involved changing the dynamic characteristics of the structure by applying a control force to the structure through the MR damper, thereby achieving a damping effect. For the MR damper control system, its motion differential equation could generally be expressed as follows:

$$
[M] \ddot{x}(t)+[C] \dot{x}(t)+[K] x(t)=-[M] \Gamma \ddot{x}_{g}+[\Lambda] F,
$$

where $M$ is the structural mass matrix; $C$ is the structural damping matrix; $K$ is the structural stiffness matrix; $\ddot{x}_{g}$ represents the external incentives; $F$ is the control force

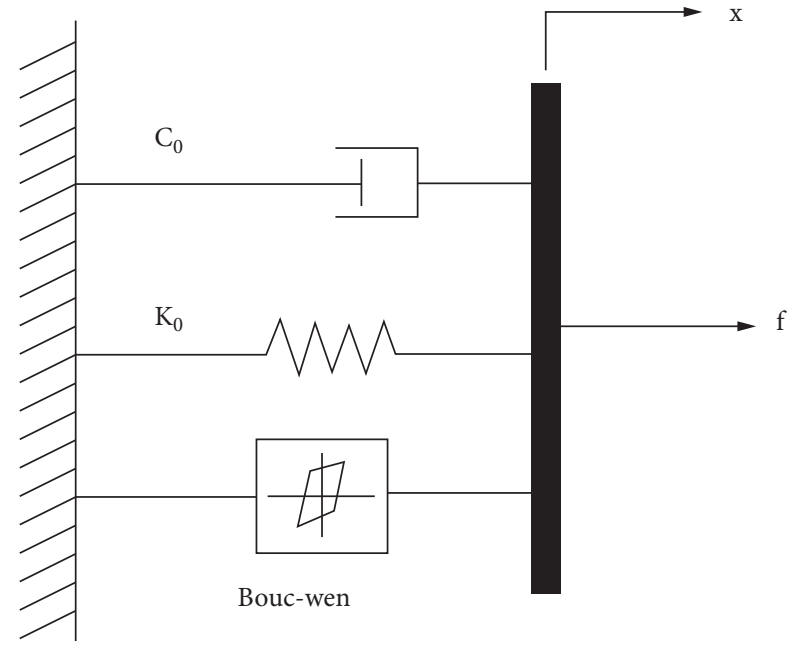

Figure 2: Schematic diagram of the Bouc-Wen model.

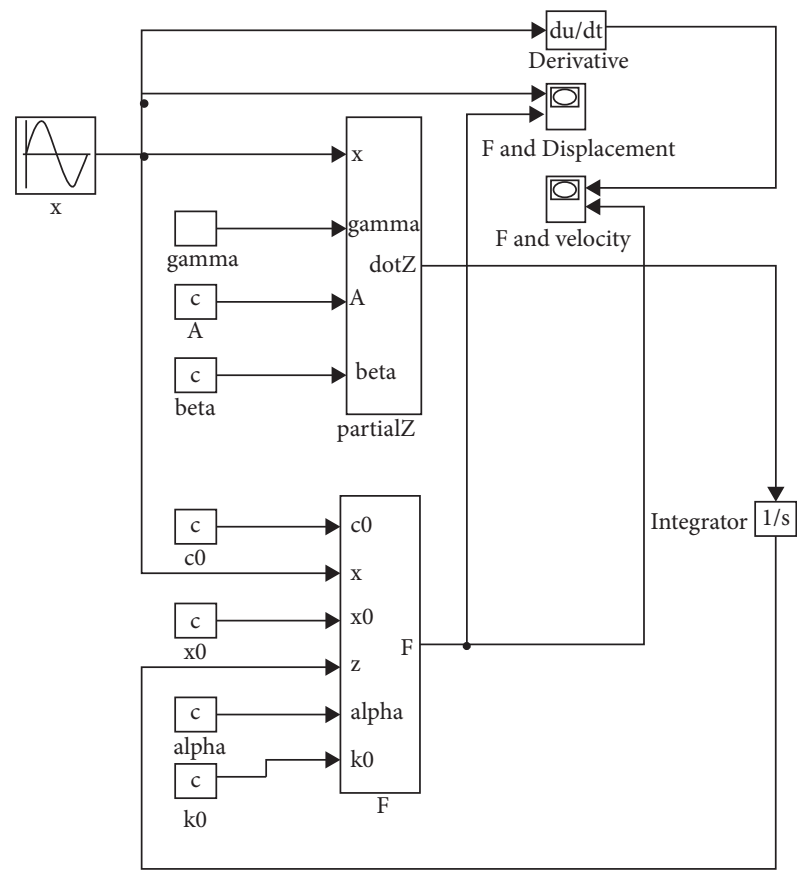

FIgURE 3: The solving chart of the Simulink simulation for the Bouc-Wen model.

provided by the MR damper; $\ddot{x}(t), \dot{x}(t)$, and $x(t)$ are the acceleration, velocity, and displacement vectors of the structure, respectively; $\Gamma$ represents the external incentives; and $\Lambda$ is the MR damping force indicator matrix.

The state vector was introduced as follows:

$$
Z(t)=\left[\begin{array}{c}
x(t) \\
\dot{x}(t)
\end{array}\right] .
$$

Then the equation of motion could be transformed into an equation of state as follows: 


$$
\begin{aligned}
& \dot{Z}(t)=[A] Z(t)+[B] u+[E] \ddot{x}_{g}, \\
& Y(t)=[C] Z(t)+[D] F,
\end{aligned}
$$

where $A$ and $C$ are the characteristic matrices describing structural systems, $B$ and $D$ are the performance parameter matrices of the MR damper, and $E$ is the external stimulus position matrix. In the simulation analysis of the $M R$ damper vibration reduction, the optimal control force $F$ was determined by solving the state equation.

4.1. Realization of the Passive Control Method for the MR Damper. In this investigation, the Bouc-Wen MR damper mechanical model was selected for vibration reduction research. The model used the reciprocating displacement $x$ and the velocity $\dot{x}$ of the structural vibration to change the control force of the MR damper. An RD-8041-1 MR damper [36] produced by the United States LORD company was selected to study the vibration damping control of the structure. This type of MR damper controls a damper by controlling the input current. Therefore, the passive control of this MR damper included two modes: passive-off (the current was zero) and passive-on (the current was not zero). Through the secondary development of Abaqus, the passive control of the MR damper was achieved. The overall idea was that for the constant current state, the control force of the MR damper calculated by the Bouc-Wen model was equivalent to an equivalent uniform load that was applied to the corresponding damping control area to achieve the MR damping passive control of the device. The flow of the passive control algorithm of the MR damper is shown in Figure 4, which specifically includes the following steps:

(1) The displacement $x$ and the velocity $\dot{x}$ of each incremental step of the control point were obtained with the URDFIL subroutine, and the data was stored in the global variable COMMON block. The displacement keyword in the fil file was 101, and the speed was 102 .

(2) In the constant current state, according to the displacement $x$ and the velocity $\dot{x}$, the Bouc-Wen MR damper mechanical model was used to calculate the control force $F$ of each incremental step, and the data was stored in the global variable COMMON block.

(3) The control force $F$ was transferred to the subroutine DLOAD through the global variable COMMON block, thereby applying the control force $F$ to the corresponding control area.

(4) The above process was repeated for each incremental step until the end of the program.

4.1.1. URDFIL Subroutine. The URDFIL subroutine is used to read the data in the result file (.fil) at the end of the increment. In this research, the URDFIL subroutine is used to read the displacement and speed of each incremental step of the control point.

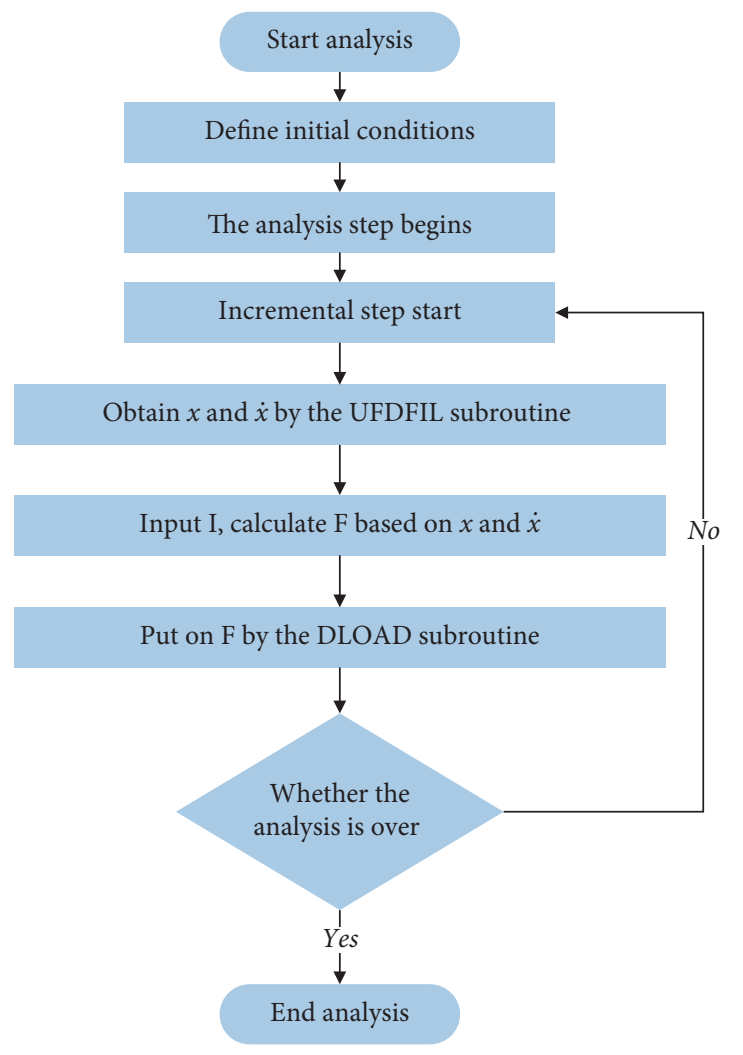

FIgURE 4: The flow chart of the passive control algorithm for the MR damper.

The flow chart of the URDFIL subroutine is provided in Figure 5.

In Figure 5, $N$ represents the number of monitoring points; $M$ represents the number of finite element model nodes; and Key is also the keyword defined in the subroutine. The diagram above shows the flow chart of the URDFIL subroutine.

(1) All parameters are entered into the subroutine

(2) Determine whether $N$ and $M$ are equal

(3) If $N$ is equal to $M$, get the value of the keyword and read the corresponding data of the keyword

(4) Output the read data

4.1.2. DLOAD Subroutine. The DLOAD subroutine could be called at each integration point to customize the nonuniformly distributed pressure load that changes with position, time, element, and node number. In this research, the DLOAD subroutine is used to apply damping force to the control area of the MR damper in each incremental step

The flow chart of the DLOAD subroutine is provided in Figure 6.

In Figure 6, $I$ represents the input current; $X$ and $V$ represent the displacement and velocity obtained through the URDFIL subroutine respectively; SNAME represents the name of the loading surface; FNAME represents the name of the surface in the finite element model; and 11 is the parameter of the 


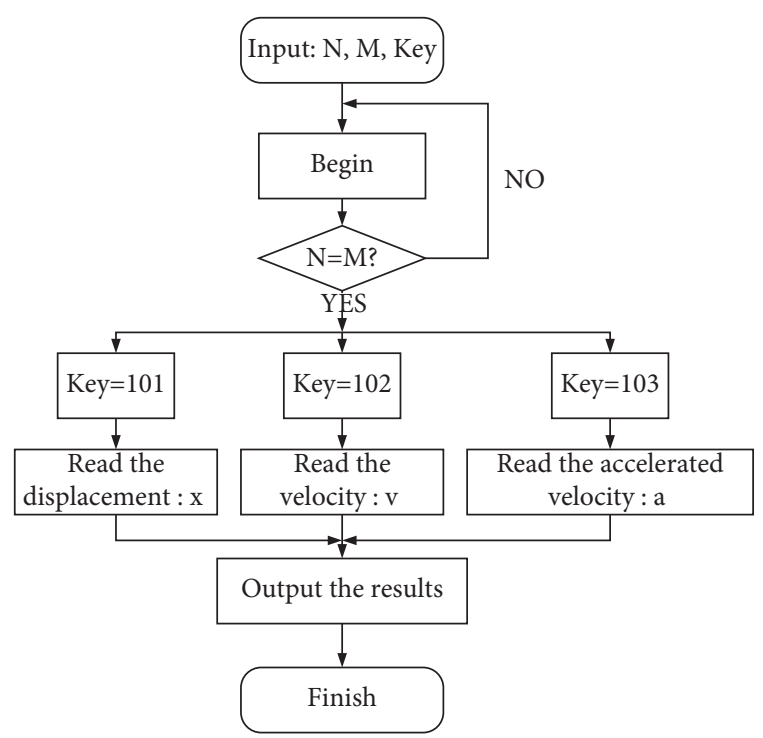

Figure 5: The flow chart of the URDFIL subroutine.

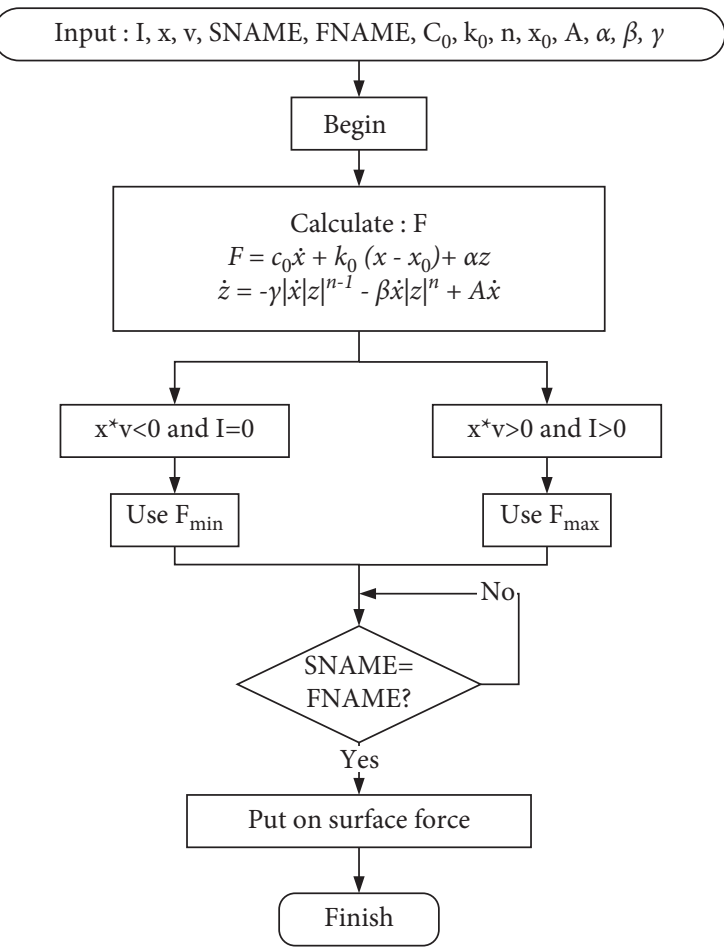

Figure 6: The flow chart of the DLOAD subroutine.

magnetorheological damper. The diagram above shows the DLOAD subroutine flow chart.

(1) All parameters are entered into the subroutine

(2) Calculate damping force $\mathrm{F}$

(3) If $x * v$ is less than zero and $I$ is equal to zero, output $F_{\min }$; if $x * v$ is greater than zero and $I$ is greater than zero, output $F_{\max }$

(4) Determine whether SNAME and FNAME are equal
(5) If SNAME is equal to FNAME, apply surface force to the corresponding SNAME; otherwise, rejudge

4.2. Realization of the Semiactive Control Method of the MR Damper. The semiactive control belongs to the parametric control and depended on the structural response and the external excitation information [37]. The control process was to reduce the response of the structure by changing the stiffness or the damping parameters of the structure in real time with a small amount of energy. The semiactive control did not require a large amount of external energy input to provide the control force. The actuators that exert control forces require a small amount of energy in order to actively take advantage of the reciprocating relative deformation or the velocity of structural vibration. The semiactive control strived to achieve the optimal control force, so a semiactive control algorithm was needed to control the MR damper to apply the optimal control force $F$. The specific semiactive control algorithm flow of the MR damper is shown in Figure 7. The specific steps included:

(1) The displacement $x$ and the velocity $\dot{x}$ of each incremental step of the control point were obtained through the URDFIL subroutine, and the data was stored in the global variable COMMON block at the same time.

(2) According to the displacement $x$ and the velocity $\dot{x}$, the semiactive control algorithm was used to calculate the optimal control force $F^{\prime}$ of the MR damper based on the Bouc-Wen model, and the data was stored in the global variable COMMON block.

(3) The optimal control force $F^{\prime}$ was transferred to the subroutine DLOAD through the global variable COMMON block so that the control force was applied to the corresponding control area.

(4) The above process was repeated for each incremental step until the end of the program.

The current semiactive control algorithms mainly included the simple bang-bang control algorithm [38, 39], the optimal bang-bang control algorithm [40, 41], and the limited Hrovat optimal control algorithm [42, 43]. To solve the shortcoming of the simple bang-bang control algorithm, in that the acceleration would change suddenly, we proposed an improved simple bang-bang control algorithm to achieve the semiactive control of the MR damper. Figure 7 shows the response state of the structure when there was a sudden change in acceleration. As shown in Figure 8(c), there was a sudden change in acceleration in section $A B$. As shown in Figures $8(\mathrm{a})$ and $8(\mathrm{~b})$, when the speed at point $\mathrm{A}$ was zero, the structure moved from one end of the direction to the center equilibrium position. Therefore, according to the simple bang-bang algorithm, when the current of the MR damper was zero at that time, the $\mathrm{AB}$ segment applied the minimum damping coefficient. In the Bouc-Wen model, the calculated damping force is smaller when the velocity at point $A$ was zero. When the speed increased to point $B$, the damping force could reduce the structure acceleration. In 


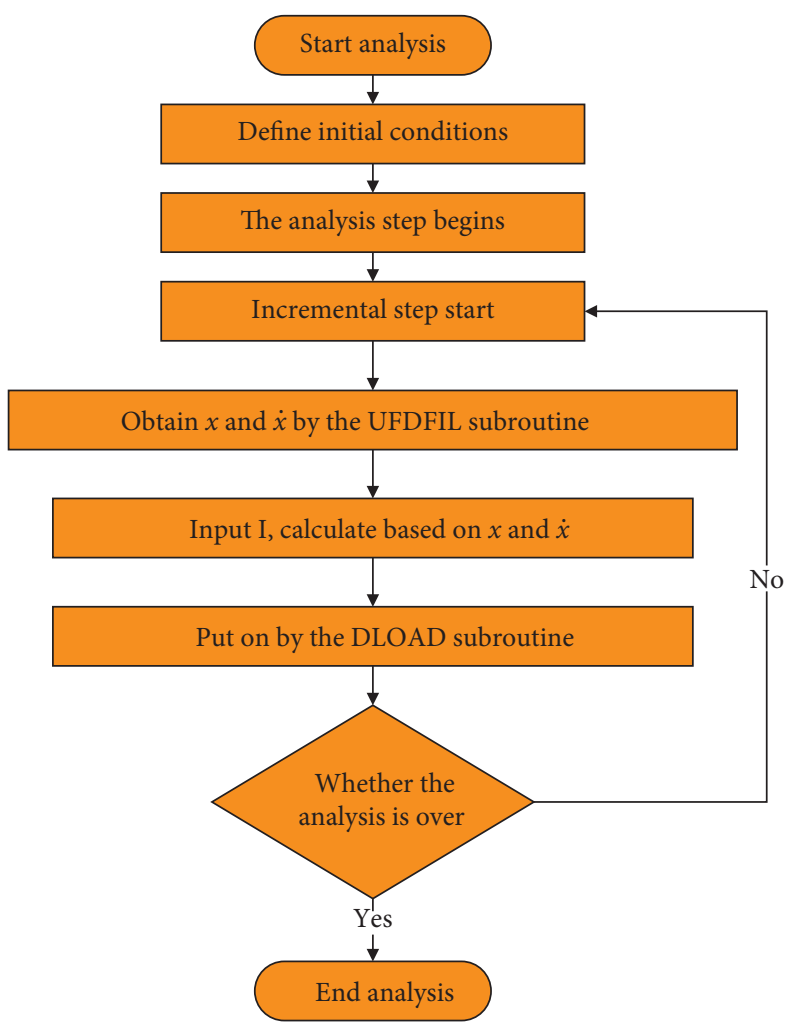

Figure 7: The flow chart of the semiactive control algorithm for the MR damper.

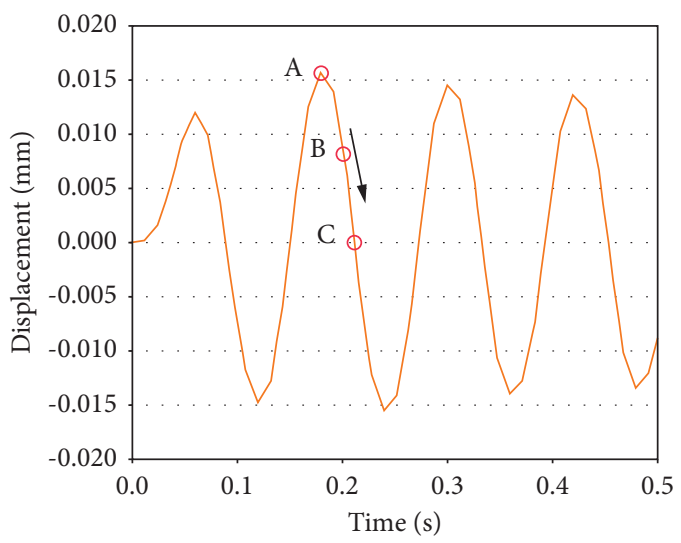

(a)

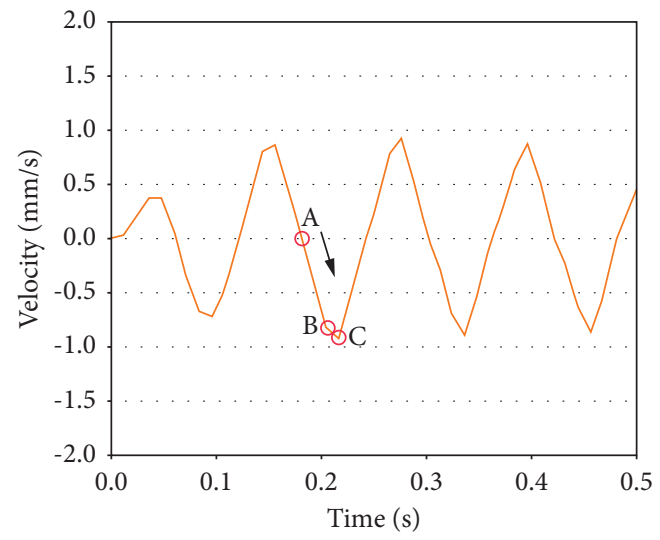

(b)

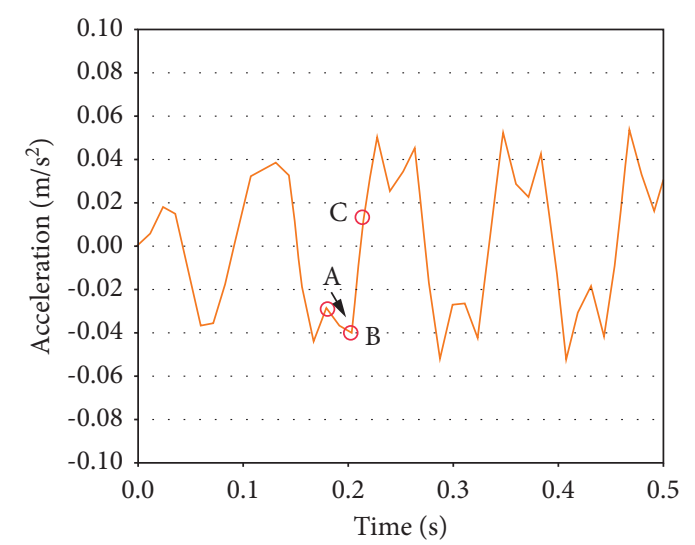

(c)

Figure 8: The response state of the structure with the sudden change of acceleration: (a) displacement, (b) velocity, and (c) acceleration. 
order to eliminate the sudden change of acceleration in the $A B$ segment, the damping force in this segment needed to be increased. In other words, the input current value of the $A B$ segment MR damper needed to be increased.

\section{Optimal Layout Method for MR Dampers}

Research has shown that increasing the number of MR dampers can improve the effect of vibration reduction control [44]. However, too many MR dampers will increase the cost, the weight of a system, and the difficulty of construction. At the same time, the time required for data collection, analysis, calculation, and control signal input and output will become longer, and the probability of failure of the control device, the maintenance cost, and the probability of system failure will also increase. Under the premise of not affecting the function of a plant [45], the vibration reduction effect and the requirements for the use of plant space are comprehensively considered to maximize the vibration reduction effect of a plant. When arranging MR dampers, the arrangement and spatial distribution of MR dampers should be selected reasonably to maximize the effect of vibration reduction.

The previous research results have shown that the vertical velocity and acceleration of a generator floor are relatively large [46]. Under no-load conditions, two-phase short-circuit conditions, and half-pole short-circuit conditions, the vertical speed and acceleration exceeded the vibration control standard values. Therefore, in this research, the control of the vertical speed and the vertical acceleration of the generator floor were mainly considered. With the premise of a certain number of MR dampers, the objective function was to minimize the vertical velocity and acceleration of the generator floor. The optimal arrangement of MR dampers could be expressed as the following multiobjective function optimization problem:

$$
\min f(x)=\left\{\begin{array}{l}
\min f_{A}(x), \\
\min f_{V}(x),
\end{array}\right.
$$

where $f_{A}(x)$ is the objective function of the vertical acceleration response, $f_{V}(x)$ is the vertical velocity response objective function, and $x$ is the MR damper layout scheme.

In most engineering optimization problems, multiple objectives need to be optimized at the same time, and the optimization process needs to maximize or minimize multiple objective functions at the same time. The multiobjective optimization problem can be expressed as follows:

$$
\begin{aligned}
\min f(x) & =\min \left[f_{1}(x), f_{2}(x), \cdots f_{n}(x)\right], \\
\mathbf{X} & =\left[x_{1}, x_{2}, \cdots x_{n}\right]^{T} \in E^{n}, \\
\text { s.t. } g_{i}(x) & \leq 0, \quad i=1,2, \cdots, m,
\end{aligned}
$$

where $f_{i}(x)$ is the optimized subobjective function, $\mathbf{X}=$ $\left[x_{1}, x_{2}, \cdots, x_{n}\right]^{T}$ is the decision vector, and $g_{i}(x)$ represents the restrictions.

In the multiobjective optimization problem shown in Figure 8 , the two objective functions $f_{1}(x)$ and $f_{2}(x)$ were contradictory. As shown in Figure 9, $A_{1}<B_{1}$ and

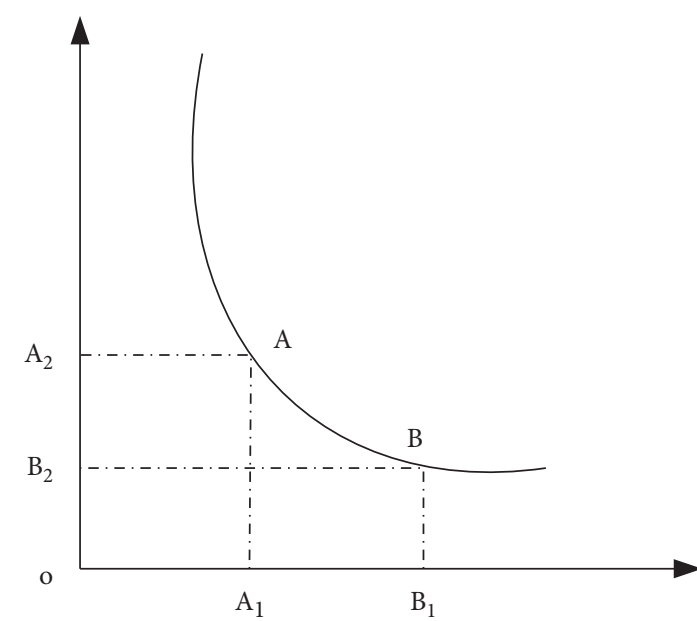

Figure 9: The problem of multiobjective optimization.

$A_{2}>B_{2}$, that is, if one objective function was improved, another objective function reduction is required as the cost; hence, solutions $\mathrm{A}$ and $\mathrm{B}$ of the multiobjective optimization problem were called noninferior solutions or Pareto optimal solutions. The Pareto optimal solution was a set in which each Pareto optimal solution was only a noninferior solution, and the multiobjective optimization problem searched for these Pareto optimal solutions [47].

The current method for solving multiobjective optimization problems is generally to convert multiobjective problems into single-objective function optimization problems. The methods of using genetic algorithms to solve multiobjective optimization problems Pareto solutions mainly include $[48,49]$ the weight coefficient method, the vector evaluation method, the maximum and minimum value method, the parallel selection method, and the shared function method. In this research, the weight coefficient method was used to solve the multiobjective function. For a multiobjective optimization problem, each subobjective function $f_{i}(x)(i=1,2, \cdots, n)$ was assigned a corresponding weight $w_{i}(i=1,2, \cdots, n)$. Therefore, a multiobjective optimization problem could be transformed into a single-objective optimization problem, and its mathematical expression could be expressed as follows:

$$
f(x)=\sum_{i}^{n} \omega_{i} \cdot f_{i}(x) .
$$

Then through the weight coefficient method, the multiobjective optimization problem of formula (7) was transformed into the following single-objective optimization problem:

$$
f(x)=\omega_{A} f_{A}(x)+\omega_{V} f_{V}(x),
$$

where $f_{A}(x)$ is the objective function of the vertical acceleration response, $f_{V}(x)$ is the vertical velocity response objective function, $\omega_{A}$ is the objective function weight coefficient of the vertical acceleration response, $\omega_{V}$ is the objective function weight coefficient of the vertical velocity response, and $x$ is the MR damper layout scheme. 
With the premise of considering the principle of symmetry as far as possible between the center of mass and the center of rigidity, an optional position where the dampers could be arranged was selected according to the structural characteristics of the hydropower plant and the requirements of space use. After determining the optional installation position of the MR damper, a suitable coding method was proposed to encode the damper, and the spatial position information of the damper was converted into a code that could be recognized by the genetic algorithm.

When optimizing the layout, the number of dampers needed to be fixed, and the population needed to ensure the same number of dampers during initialization, mutation, and crossover. Finally, through the genetic algorithm, the optimal layout of the MR damper could be obtained to meet the space requirements of the hydropower plant.

5.1. Programming of the Optimal Arrangement of $M R$ Dampers. At present, there are two methods for the secondary development of Abaqus, using Fortran for the solution level and Python for the pre- and postprocessing levels. Based on the multiobjective genetic algorithm, in this research, Python scripts and Fortran were used to perform the secondary development of Abaqus to achieve the optimization program of the MR damper of the hydropower plant structure. The flowchart is illustrated in Figure 10. The pre- and postprocessing module adopted Python scripting language for secondary development, and the solving module adopted Fortran for the secondary development of subroutines. The specific steps were as follows:

(1) In the Abaqus preprocessing module, the optional installation position of the MR damper was binary coded, and the position matrix of the MR damper was initialized.

(2) The position matrix was decoded, and the installation position of the MR damper was active with the Python script, that is, the surface applied by the load at that position was active.

(3) The vibration reduction was calculated with Abaqus.

(4) The objective function value was extracted from the result file ODB through a Python script, and the function fitness value was calculated. Subsequently, the operator was operated through the selection, crossover, and mutation of the genetic algorithm to obtain a better offspring population. This progeny population was a new MR damper position matrix.

(5) Steps 2, 3, and 4 were repeated until the end of the calculation.

(6) The optimal position matrix of the MR damper was decoded and output.

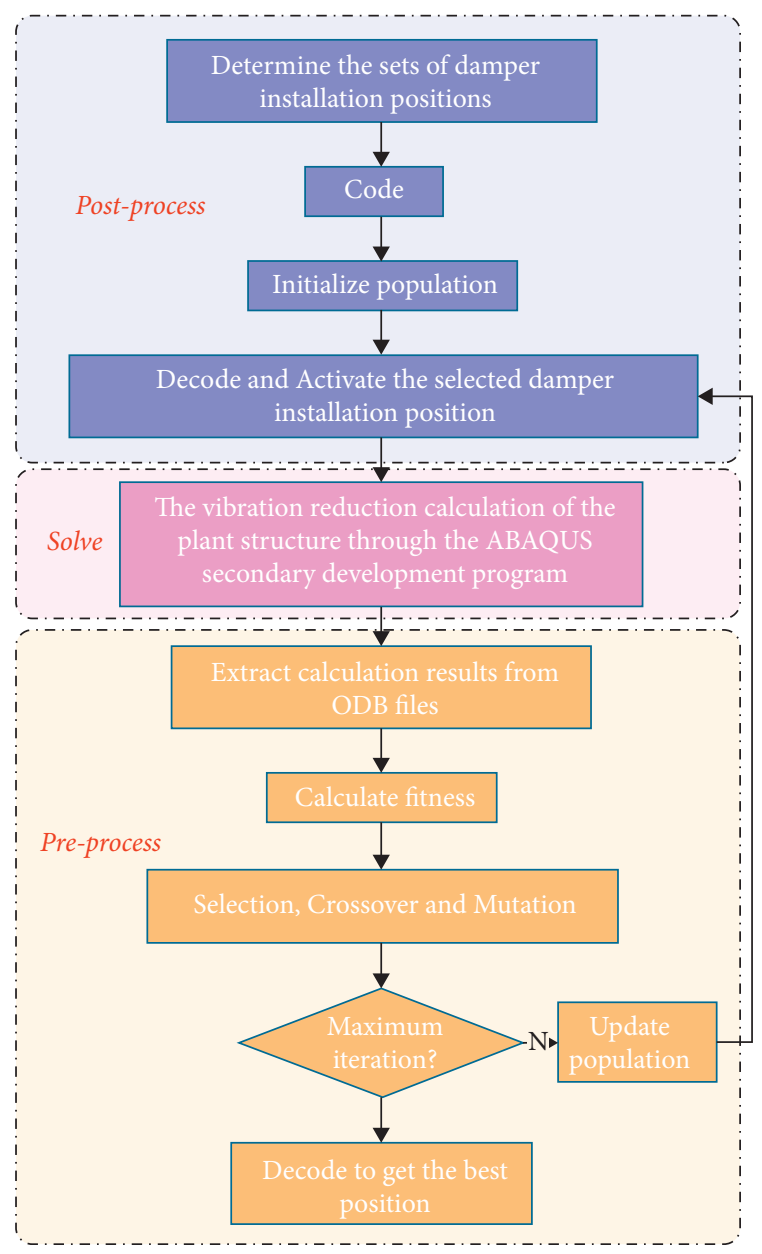

FIGURE 10: Flow chart of MR damper optimal layout program.

5.2. MR Damper Position Coding. When using genetic algorithms to solve optimization problems in engineering, we first used a reasonable coding method to properly represent the solution space of the optimization problem. Before optimizing the arrangement of the MR damper, we first selected all of the positions $N$ where the damper could be installed according to the structural characteristics, and we numbered the selected installation positions. The arrangement information of the MR damper could be represented by a tuple $S(n, i)$, where $n(n \in 1,2, \cdots, N)$ is the installation position number of the MR damper and $i$ indicates whether the damper was installed here ( 1 means installation and 0 means no installation). Therefore, the optional installation positions of the MR dampers in the plant structure were binary coded in sequence. The length of the chromosome was equal to the total number $N$ of possible positions in the structure. Assuming that the number of optional arrangements of MR dampers was 12 and the number of dampers selected was 6 , the chromosome could be expressed as follows: 


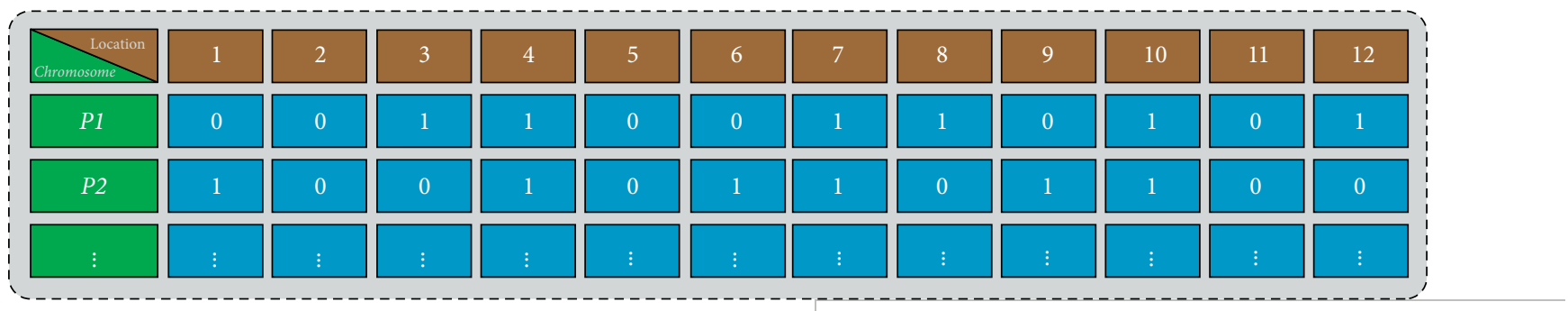

Chromosome P1 $=[001100110101]$ means that the MR damper was arranged at positions $3,4,7,8,10$, and 12 . Chromosome P2 $=[100101101100]$ indicates that the MR damper was arranged at positions $1,4,6,7,9$, and 10. Through the above coding method, the spatial information of the MR damper arrangement could be transformed into a code that could be recognized by the genetic algorithm.

5.3. Initialization of the Population. After determining the encoding method of the MR damper, the arrangement scheme of the MR damper was coded through population initialization. In the genetic algorithm, the initialization of the population involved generating the initial population of the required individuals through a random method. The initialized population was a two-dimensional array $P$, with the rows representing each arrangement plan and the columns representing the position of the damper for choosing the arrangement.

$$
P=\left[\begin{array}{ccc}
P_{1}^{1} & \cdots & p_{1}^{n} \\
\vdots & \ddots & \vdots \\
P_{a}^{1} & \cdots & p_{a}^{n}
\end{array}\right]
$$

where $a$ is the population size and $n$ is the chromosome length, which was equal to the number of optional positions.

The number of dampers to be installed for the space optimization problem of the MR dampers was fixed, so the number of MR dampers in the initialization unit needed to be restricted. According to the coding method, the value of a chromosome was either 0 or 1 . If the number of dampers was set to $m$, the constraint condition could be expressed as follows:

$$
\sum_{i}^{n} t_{i}=m
$$

where $n$ is the chromosome length, and $t_{i}$ is the value on the $i$-th chromosome. Therefore, the constraint conditions could ensure that each individual obtained by initialization contained $m$ dampers, thus ensuring the correctness of the chromosome. The size of the population had a great influence on the performance of genetic algorithms. The population size was too large to increase the calculation time, which caused the competitive advantage over other methods to be lost. The population size was too small, which makes it difficult to satisfy the species diversity. It is possible that the population did not contain the optimal gene at the beginning, and it was difficult to find the potential optimal individual during the evolution process. In that case, the competitiveness between individuals was not great, which caused the genetic algorithm to greatly reduce the optimization ability. Therefore, selecting an appropriate population size was the key starting point for the entire genetic algorithm. This step had to ensure that the initial population cause essentially contain all possible genes in order to find the optimal individual as soon as possible. According to the experience of other researchers $[49,50]$, the population size was usually set to $20-100$.

5.4. Fitness Function. Fitness is an index used to measure the pros and cons of individuals, and it is also the only basis for natural selection. Individuals with high fitness are more likely to be selected and inherited to the next generation. For the optimal placement of the MR dampers in the plant structure, the response of the plant structure was taken as the objective function (see equation (8)) to calculate the fitness value. Therefore, the larger the fitness value, the smaller the objective function value, and the better the individual, which indicated that the optimally arranged MRD had a better vibration damping effect.

The fitness function had to satisfy the conditions of [36, 37]: (1) being single value, continuous, nonnegative, and maximized; (2) being reasonable and consistent; (3) having a small amount of calculation; and (4) having strong versatility. For the minimum objective function, the fitness function is as follows:

$$
\begin{aligned}
\{F\} & = \begin{cases}\left\{C_{\max }\right\}-\{f(x)\}, & \{f(x)\}<\left\{C_{\max }\right\}, \\
0, & \text { other, }\end{cases} \\
{[K]\{u\} } & =\{F\}, \\
\{u\} & =\left\{\begin{array}{l}
v \\
a
\end{array}\right\}, \\
\{F\} & =c_{0} \dot{x}+k_{0}\left(x-x_{0}\right)+\alpha z, \\
\{f(x)\} & =\{u\}=[K]^{-1}\{F\},
\end{aligned}
$$

where $\left\{C_{\max }\right\}$ is the maximum estimate of $\{f(x)\},[K]$ is the system characteristic matrix, and $\{u\}$ is the state variable contains the velocity and the acceleration. The above fitness function fully reflected the differences between individuals. Among them, good individuals could gain a greater chance of survival, while poor individuals were eliminated with a greater probability. 


\subsection{Selection, Crossover, and Mutation}

5.5.1. Select Operation. Natural selection involves selecting excellent individuals from an old population to form a new population with a certain probability and obtaining the next generation of individuals through reproduction. The probability of an individual being selected is related to fitness. The greater the fitness, the higher the probability of the individual being selected. In this research, the selection operation was performed with the roulette method. The probability $P_{i}$ of the individual being selected is as follows:

$$
P_{i}=\frac{F_{i}}{\sum_{j=1}^{N} F_{j}},
$$

where $F_{i}$ is the fitness value of individual $i$ and $N$ is the number of individuals in the population.

Figure 11 shows a schematic diagram of the roulette method. The roulette wheel represents the entire population, and the area of each block in the roulette wheel is the ratio of the overall fitness of the individual to the population. For individuals with high fitness, the larger the occupied area, the higher the probability of being selected. The specific algorithm flow is as follows. The first step is to calculate the probability $P_{i}$ of all individuals being selected according to formula (18). The second step is to generate random numbers between 0 and 1 consistent with the population size and to arrange the random numbers from small to large. The third step is to compare the random number with the probability of the individual being selected. Those who were less than the random number were eliminated, and those who were greater than the random number were left. Through the roulette method, the excellent individuals with high adaptability could be selected, and the individuals with low adaptability could be eliminated.

5.5.2. Crossover Operation. The crossover operation involved randomly selecting two individuals from the population, exchanging and combining the chromosomes of the

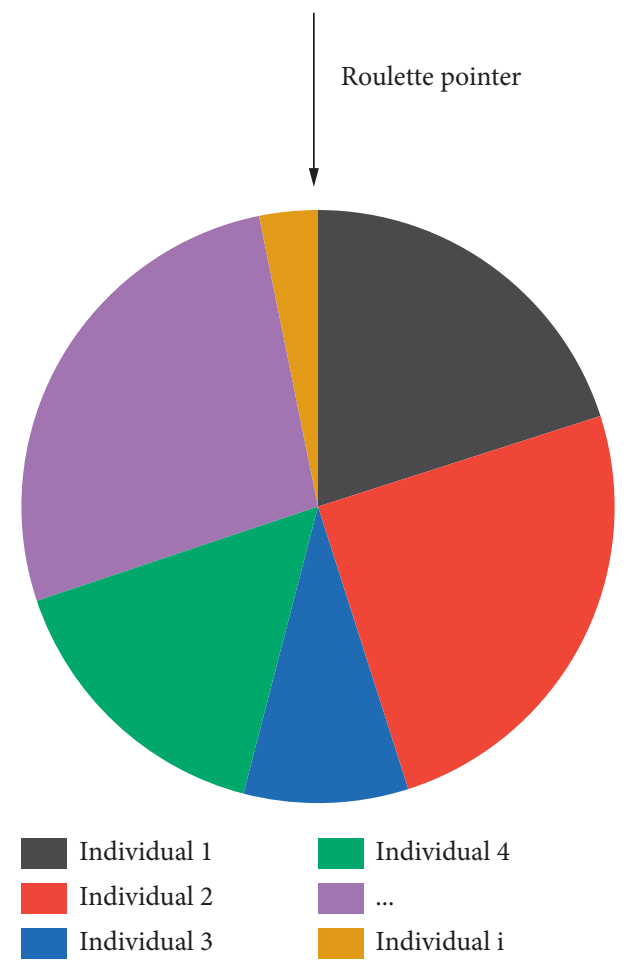

FIGURE 11: The sketch of the roulette method.

two individuals, and causing the excellent genes of the parent to be inherited by the offspring, thereby forming a better individual. In the optimizing placement of the MR dampers, the new entity obtained by crossover needs to meet the constraint condition of the constant number of dampers. Therefore, the specific crossover algorithm could be described as follows.

It was assumed that the two selected individuals to cross were $\mathrm{P} 1$ and $\mathrm{P} 2$, for which the individual chromosome length was 12, and the number of MR dampers was 6 .

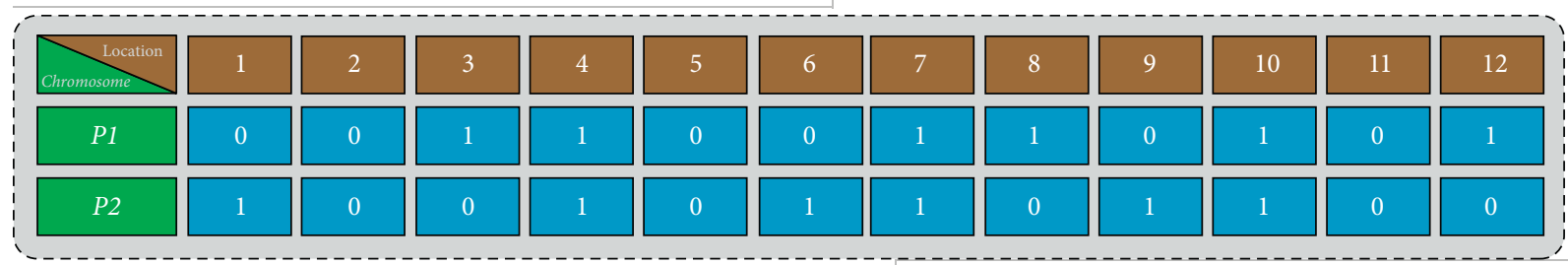

The number of dampers needed to be kept constant for each crossover, so the crossover position needed to be selected correctly. The specific method is as follows. The first step is to accumulate the values of the chromosomes in the individual one by one. Then the accumulation result of P1 and $\mathrm{P} 2$ is as follows:

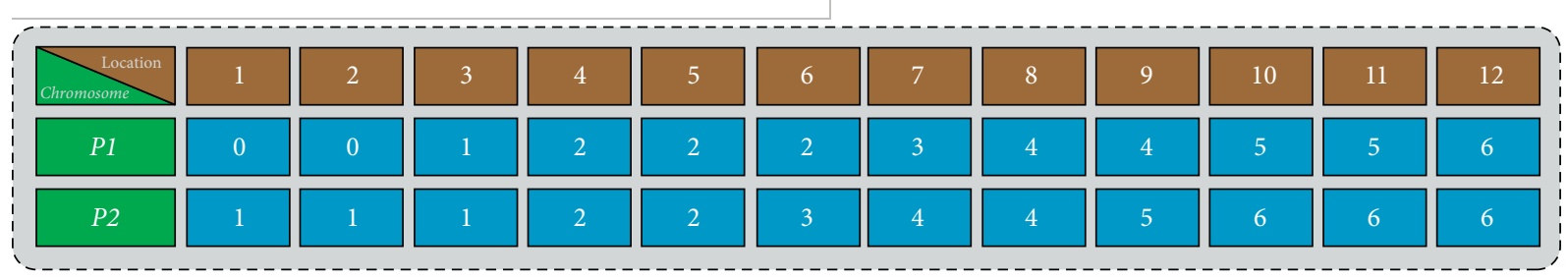


The second step was to compare the cumulative results of two crossover individuals. If the cumulative results were the same at the same position, the position was the crossover position. Therefore, the cross positions of $\mathrm{P} 1$ and $\mathrm{P} 2$ were 3 , 4,5 , and 8 , respectively $[3-5,8]$.

The third step was to randomly select a position among the four optional positions for crossover operation.

The crossover probability determined the frequency of the crossover operation, which had a greater impact on the entire optimization process. If the crossover probability was too high, too many new individuals would be generated, making it difficult for the calculation to converge. If the crossover probability was too small, the newly generated individual would be poor, and the result might fall into the local optimal solution prematurely. Generally, the crossover probability was between 0.4 and $0.9[49,50]$.

5.5.3. Mutation Operation. The purpose of mutation was to maintain the diversity of the population. The mutation involved randomly selecting an individual from the population, selecting a certain gene in the individual to mutate, and producing a new outstanding individual. To solve the problem of optimizing the arrangement of the MR dampers, the constraint condition that the number of MR dampers remained unchanged also needed to be satisfied after the mutation. Therefore, when mutating, two genes needed to be randomly selected: gene 1 and gene 0 . During mutation, gene 1 became 0 , and gene 0 became 1 to ensure that the number of MR dampers remained unchanged during the mutation process.

The probability of mutation had a greater impact on the optimization process of the genetic algorithm. The selection of the mutation probability was affected by factors such as the population size and the chromosome length. If the mutation probability was too large, it would lead to the instability of the algorithm; if the mutation probability was too small, the ability of the newly generated individual would be poor and the algorithm would become premature. Normally, the probability of mutation was $0.001 \sim 0.1$ $[49,50]$.

\section{Engineering Case Analysis}

6.1. Calculation Model and Parameter Selection. The entire calculation model was gridded into 214,087 units and 52,724 nodes (see Figure 12). The origin of the coordinates is set at the center of the generator floor. The $x$ direction of the coordinate system was the longitudinal axis of the plant; the $y$ direction was the upstream and downstream direction of the plant; and the $z$ direction was the vertical direction. The material parameters of the plant structure are shown in Table 1. Among them, the concrete strength grade of the factory floor, beams, pillars, machine piers, windshield, and spiral casing was $\mathrm{C} 30$, and the concrete strength grade of the rest was C25.

Research has shown that under no-load conditions, the damping control effect of MR dampers is poor [51]. Therefore, in this research, this operating condition was

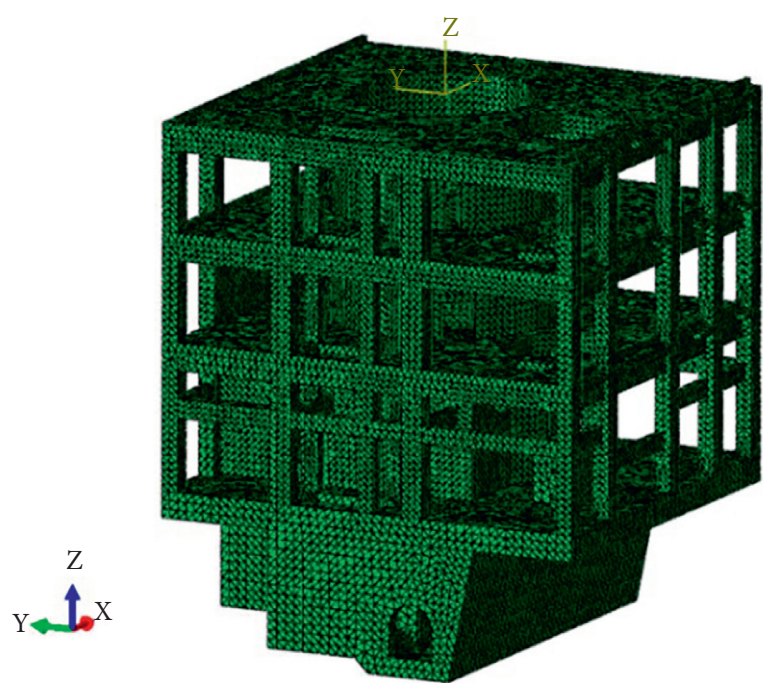

FIgURE 12: The mesh model of the powerhouse.

selected in order to study the optimal layout of MR dampers. It was assumed that various vibration loads were simple harmonic loads. The position and the magnitude of each load are shown in Table 2.

The time history of the external force couple is given by $F(t)=f(t) \times F_{D}$, where the time variation factor $f(t)$ is depicted in Figure 13 and $F_{D}$ is the standard loading value of the unit.

In this research, the minimization of vertical speed and the acceleration were taken as the optimization objective function. Taking the no-load condition as an example, the multiobjective genetic algorithm was used to optimize the layout of the MR damper on the generator floor. The parameters used in the genetic algorithm are shown in Table 3. The population size was 20; the chromosome length was 22; the maximum number of iterations was 30 ; and the crossover and mutation probabilities were 0.8 and 0.05 , respectively. The objective function was calculated according to formula (10), for which $\omega A$ and $\omega V$ were both selected as 0.5 . When using the compiled program to calculate the optimal layout, taking the calculation efficiency into consideration, the passive-on control method was adopted to optimize the layout of the MR damper in the powerhouse.

In order to obtain a better vibration reduction effect, the MR damper should be installed in the large response area of the structure. At the same time, the principle of symmetry between the center of mass and the center of stiffness should be considered, as well as the requirements of the use of structural space. The MR damper was installed in the midspan position of the beam to control the first vibration mode, in combination with the structural characteristics of the generator floor, as shown in Figure 14. The MR damper parameters are shown in Table 4. In this research, 22 optional MR damper installation positions were selected (the positions are shown in Table 5). Twelve damper installation positions in the optional positions were selected to control the vibration of the powerhouse. 
TABLE 1: The parameters of the powerhouse.

\begin{tabular}{lccc}
\hline Material & Static elastic modulus $\left(10^{4} \mathrm{MPa}\right)$ & Severe $\left(\mathrm{kN} \cdot \mathrm{m}^{-3}\right)$ & Poisson's ratio \\
\hline Steel & 20.60 & 78.0 & 0.300 \\
C25 concrete & 2.80 & 25.0 & 0.167 \\
C30 concrete & 3.00 & 25.0 & 0.167 \\
\hline
\end{tabular}

TABLE 2: The standard loading value of the unit (units: $\mathrm{kN}$ ).

\begin{tabular}{|c|c|c|}
\hline & & Backfill gravel \\
\hline \multirow{3}{*}{ Stator } & Axially V1 & $1,379.0$ \\
\hline & Tangential T1 & 0.0 \\
\hline & Radial R1 & 0.0 \\
\hline \multirow{3}{*}{ Lower bracket } & Axially V2 & 24.5 \\
\hline & Tangential T2 & 18.9 \\
\hline & Radial R2 & 18.9 \\
\hline Upper bracket & Radial R3 & 48.8 \\
\hline
\end{tabular}

$f(t)$

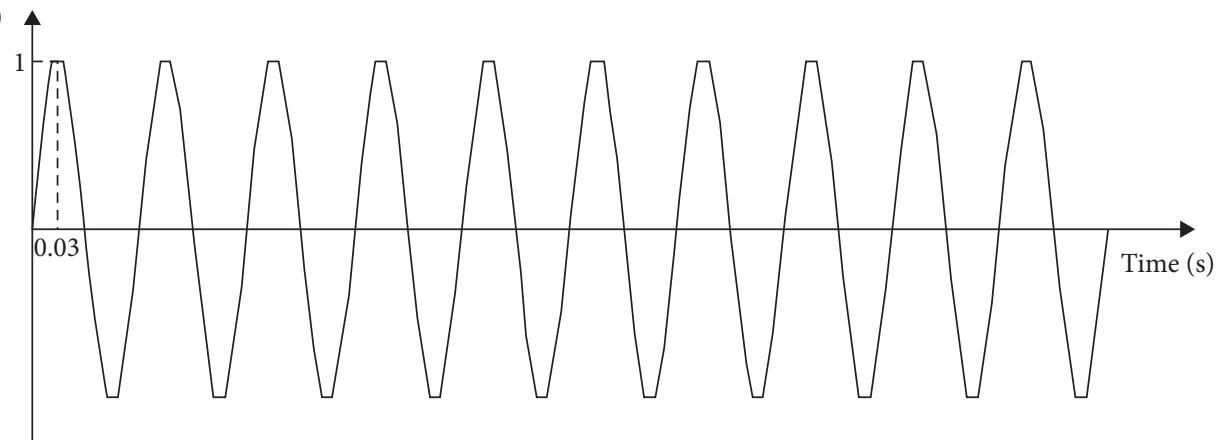

Figure 13: Time variation factor $f(t)$ of force couple.

TABLE 3: The parameters of the genetic algorithm.

\begin{tabular}{lcccc}
\hline Population size & Chromosome length & Crossover probability & Mutation probability & Maximum number of iterations \\
\hline 20 & 22 & 0.8 & 0.05 & 30 \\
\hline
\end{tabular}

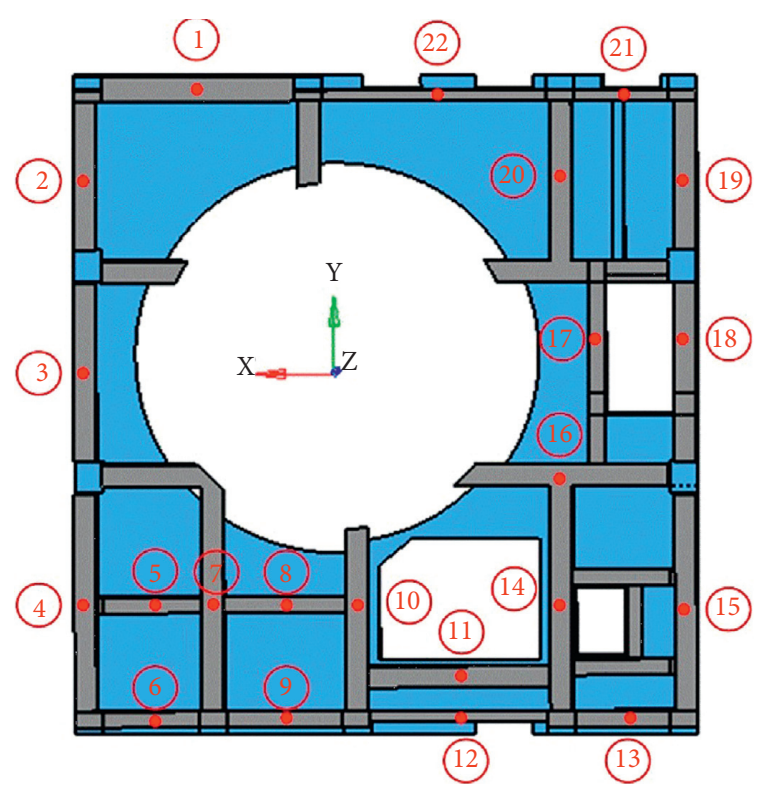

FIgURE 14: The installation location of the MR dampers.
TABLE 4: The parameters of the MR dampers.

\begin{tabular}{lc}
\hline Parameter & Value \\
\hline$A$ & 53.17 \\
$\alpha$ & 862.30 \\
$\beta$ & 36.37 \\
$\gamma$ & 47.46 \\
$C_{0}$ & 2.245 \\
$K_{0}$ & 1.31 \\
$n$ & 1.24 \\
$x_{0}$ & -20.75 \\
\hline
\end{tabular}

6.2. Vibration Reduction Effect after Optimized Layout. Table 6 and Figure 13 illustrate the optimized layout results of the MR dampers on the generator floor. It can be seen from Figure 15 that when the genetic algorithm was iterated to about 16 generations, the optimized solution tended to converge. It can be seen from Table 6 that the target value converged to 1.547 , and the subobjective function values of the velocity and the acceleration were $2.493 \mathrm{~mm} / \mathrm{s}$ and $0.601 \mathrm{~m} / \mathrm{s}^{2}$, respectively. According to the optimized 
TABLE 5: The coordinate of the installation locations of MR dampers.

\begin{tabular}{|c|c|c|c|c|}
\hline Structure & Control point & Control point coordinates & Control point & Control point coordinates \\
\hline \multirow{11}{*}{ Generator floor } & 1 & $(5.00,9.85)$ & 12 & $(-4.65,-13.10)$ \\
\hline & 2 & $(9.10,6.90)$ & 13 & $(-10.54,13.10)$ \\
\hline & 3 & $(9.10,0.00)$ & 14 & $(-8.10,-9.10)$ \\
\hline & 4 & $(9.10,-9.10)$ & 15 & $(-12.60,-9.10)$ \\
\hline & 5 & $(6.96,-9.10)$ & 16 & $(-8.05,-4.40)$ \\
\hline & 6 & $(7.00,-13.10)$ & 17 & $(-9.10,0.01)$ \\
\hline & 7 & $(4.50,-9.10)$ & 18 & $(-12.60,0.01)$ \\
\hline & 8 & $(2.14,-9.10)$ & 19 & $(-12.6,6.90)$ \\
\hline & 9 & $(1.90,-13.10)$ & 20 & $(-8.10,6.90)$ \\
\hline & 10 & $(-0.01,-9.10)$ & 21 & $(-10.54,9.60)$ \\
\hline & 11 & $(-4.65,-11.85)$ & 22 & $(-4.06,9.60)$ \\
\hline
\end{tabular}

TABLE 6: The results of the optimal placement of the MR dampers.

\begin{tabular}{lccc}
\hline $\begin{array}{l}\text { Optimal } \\
\text { position }\end{array}$ & $\begin{array}{c}\text { Objective function } \\
\text { value }\end{array}$ & $\begin{array}{c}\text { Speed function objective function } \\
\text { value }(\mathrm{mm} / \mathrm{s})\end{array}$ & $\begin{array}{c}\text { Acceleration function objective function } \\
\text { value }\left(\mathrm{m} / \mathrm{s}^{2}\right)\end{array}$ \\
\hline $\begin{array}{l}1,2,3,4,7,14,15,16,17,20, \\
21,22\end{array}$ & 1.547 & 2.493 & 0.601 \\
\hline
\end{tabular}

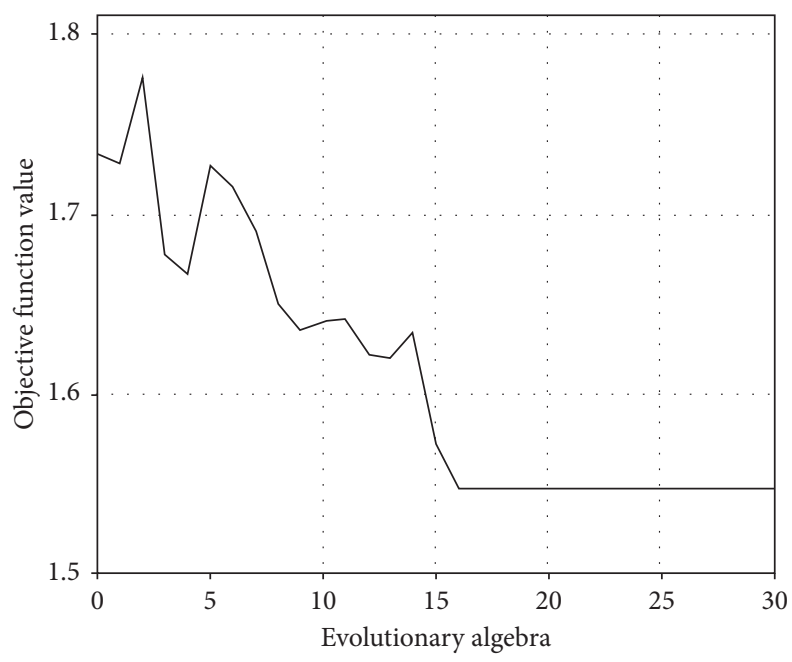

FIgURE 15: The evolution process of the objective function value.

installation position of the MR damper, the semiactive control methods of improved simple bang-bang were used to control the vibration of the powerhouse.

Table 7 shows the overall maximum response value of the generator floor after the optimized layout. For the vertical velocity, after optimizing the layout, the passive control passive-on and the semiactive control improved simple bang-bang responses were $2.836 \mathrm{~mm} / \mathrm{s}$ and $2.686 \mathrm{~mm} / \mathrm{s}$, respectively, and the responses were reduced by $13.90 \%$ and $18.46 \%$, respectively. For the vertical acceleration, the responses of the passive control passive-on and the semiactive control improved simple bang-bang were $0.605 \mathrm{~m} / \mathrm{s}^{2}$ and $0.549 \mathrm{~m} / \mathrm{s}^{2}$, respectively, and the responses were reduced by $11.16 \%$ and $19.38 \%$, respectively. Before comparing the optimized layout, the optimized layout of the MR damper installation position was used for the vibration damping control, and the damping effect was improved. In particular, when the improved simple bang-bang control method was adopted, the overall maximum vertical velocity damping effect of the generator floor was increased by $5.56 \%$, and the maximum vertical acceleration damping effect was increased by $8.66 \%$.

In order to better demonstrate the damping effect after the optimized layout, Table 8 shows the response values of the characteristic points of the generator floor after the optimized layout. For the maximum vertical velocity response point after optimization, the vertical speed responses of the passive control passive-on and the semiactive control improved simple bang-bang were $2.493 \mathrm{~mm} / \mathrm{s}$ and $2.086 \mathrm{~mm} / \mathrm{s}$, respectively, and the responses were reduced by $24.32 \%$ and $36.67 \%$, respectively. For the maximum vertical acceleration response point, the vertical acceleration responses of the passive control passive-on and the semiactive control improved simple bang-bang responses were $0.601 \mathrm{~m} /$ 
TABLE 7: The maximum response of the generator floor after the optimal layout.

\begin{tabular}{lcccc}
\hline \multicolumn{1}{c}{ Response } & & No control & Passive-on & Improved simple bang-bang \\
\hline & Before optimization & 3.294 & $2.933(10.96 \%)$ & $2.869(12.90 \%)$ \\
Vertical velocity $(\mathrm{mm} / \mathrm{s})$ & Optimized & - & $2.836(13.90 \%)$ & $2.686(18.46 \%)$ \\
& Optimization effect & - & $2.94 \%$ & $5.56 \%$ \\
Vertical acceleration $\left(\mathrm{m} / \mathrm{s}^{2}\right)$ & Before optimization & 0.681 & $0.617(9.40 \%)$ & $0.608(10.72 \%)$ \\
& Optimized & - & $0.605(11.16 \%)$ & $0.549(19.38 \%)$ \\
& Optimization effect & - & $1.76 \%$ & $8.66 \%$ \\
\hline
\end{tabular}

TABLE 8: The response of the generator floor characteristic points after the optimal layout.

\begin{tabular}{|c|c|c|c|c|}
\hline Response & & $\begin{array}{c}\text { No } \\
\text { control }\end{array}$ & Passive-on & $\begin{array}{l}\text { Improved simple bang- } \\
\text { bang }\end{array}$ \\
\hline \multirow{3}{*}{$\begin{array}{l}\text { The maximum vertical velocity response point (vertical velocity; } \\
\mathrm{mm} / \mathrm{s} \text { ) }\end{array}$} & $\begin{array}{c}\text { Before } \\
\text { optimization }\end{array}$ & 3.294 & $\begin{array}{c}2.729 \\
(17.15 \%)\end{array}$ & $2.257(31.48 \%)$ \\
\hline & Optimized & - & $\begin{array}{c}2.493 \\
(24.32 \%)\end{array}$ & $2.086(36.67 \%)$ \\
\hline & $\begin{array}{l}\text { Optimization } \\
\text { effect }\end{array}$ & - & $7.16 \%$ & $5.19 \%$ \\
\hline \multirow{3}{*}{$\begin{array}{l}\text { The maximum vertical acceleration response point (vertical } \\
\text { acceleration; } \mathrm{m} / \mathrm{s}^{2} \text { ) }\end{array}$} & $\begin{array}{c}\text { Before } \\
\text { optimization }\end{array}$ & 0.681 & $0.617(9.40 \%)$ & $0.550(19.24 \%)$ \\
\hline & Optimized & - & $\begin{array}{c}0.601 \\
(11.75 \%)\end{array}$ & $0.520(23.64 \%)$ \\
\hline & $\begin{array}{c}\text { Optimization } \\
\text { effect }\end{array}$ & - & $2.35 \%$ & $4.41 \%$ \\
\hline
\end{tabular}
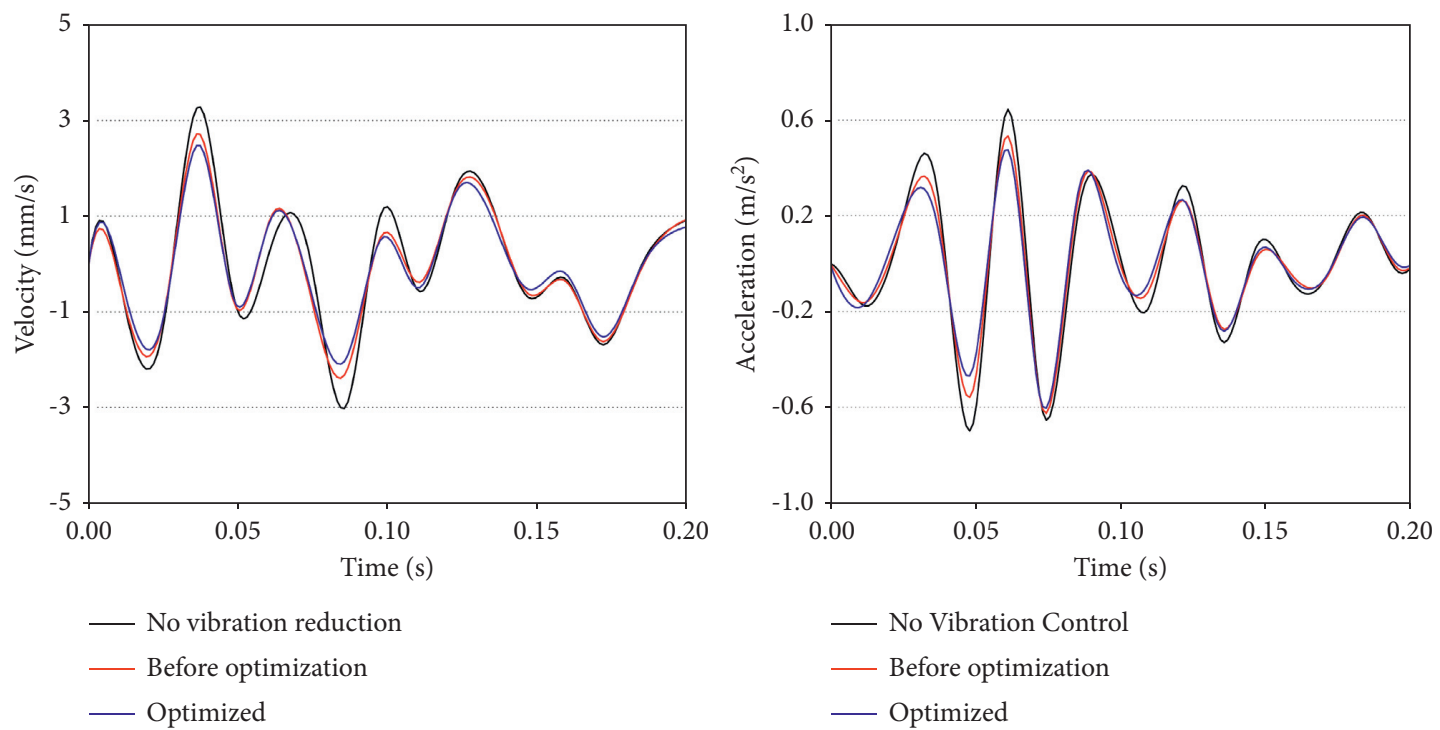

FiguRe 16: Time-history curve of characteristic points after the optimal layout for the passive-on control.

$\mathrm{s}^{2}$ and $0.520 \mathrm{~m} / \mathrm{s}^{2}$, respectively, and the responses were reduced by $11.75 \%$ and $23.64 \%$, respectively. When the improved simple bang-bang control method was adopted, the vertical velocity vibration reduction effect of the maximum vertical velocity response point of the generator floor was increased by $5.19 \%$, and the vertical acceleration vibration reduction effect of the maximum vertical acceleration response point was increased by $4.41 \%$. In addition, Figures 16 and 17 show the time history curves of the maximum response point of the two control methods. It can also be seen from the figures that the optimized arrangement effectively improved the vibration damping control effect of the MR damper.

In summary, for the no-load conditions, the overall responses of the vertical velocity and the acceleration of the generator floor were reduced by $18.46 \%$ and $19.38 \%$, respectively, by optimizing the arrangement of MR dampers. Compared with the optimized layout, the vibration reduction effect was increased by $5.56 \%$ and $8.66 \%$, respectively. The vertical velocity at the maximum vertical velocity 

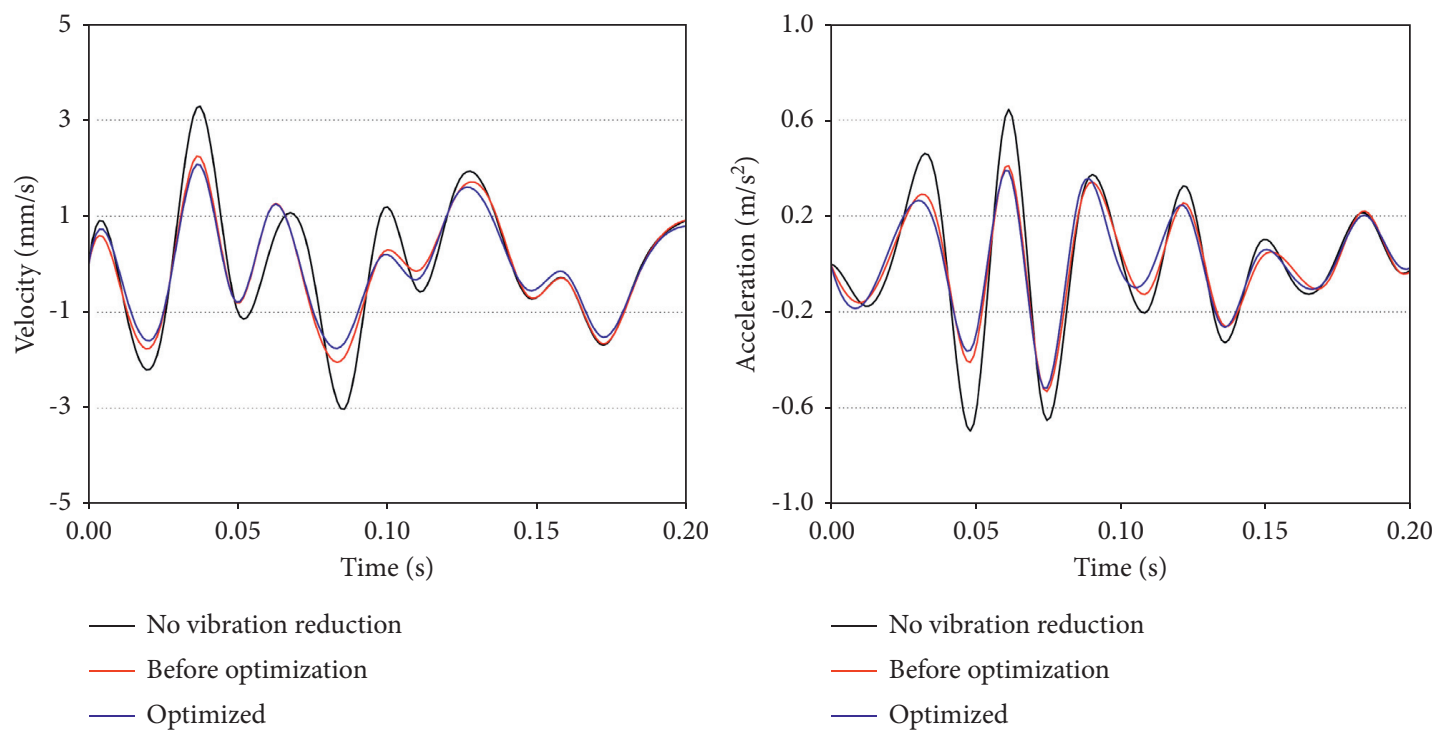

FIgURE 17: Time-history curve of characteristic points after the optimal layout for the improved bang-bang control.

response point was reduced by $36.67 \%$, and the vertical acceleration at the maximum acceleration response point was reduced by $23.64 \%$. Compared with the optimized layout, the vibration reduction effect was increased by $5.19 \%$ and $4.41 \%$, respectively. Therefore, the optimized layout method of the MR dampers for plant buildings proposed in this research could effectively improve the vibration reduction effect of the MR dampers.

\section{Conclusions}

Based on the engineering background of an existing pumped-storage power plant, in this research, two aspects are mainly discussed and researched: the numerical simulation method of MR damper vibration reduction control and the optimal arrangement of an MR damper. The main conclusions were as follows:

(1) Based on the Bouc-Wen model, we proposed a calculation method for an MR damper that was suitable for large and complex structures. Through the secondary development of the Abaqus platform, the passive control (passive-off and passive-on) and semiactive control of the MRD were realized. The method was simple and easy to implement by simply controlling the current switch of the MR damper. Additionally, the size could achieve the passive control and semiactive control of the MR damper.

(2) In view of the large vertical velocity and acceleration response of the generator floor, we took minimizing the vertical velocity and acceleration as the optimization objective function, and we established a multiobjective optimization problem for the optimal placement of the MR dampers. Based on the multiobjective genetic algorithm, Abaqus was redeveloped through Python and Fortran, and the MR damper on the generator floor of the plant was optimized. The results showed that the optimized layout method of the plant MR damper proposed in this research was effective and feasible, and the damping effect of the damper could be effectively improved through the optimized layout.

\section{Data Availability}

The codes used in this paper are available from the author upon request.

\section{Conflicts of Interest}

The authors declare that there are no conflicts of interest regarding the publication of this paper.

\section{Acknowledgments}

This research was funded by the National Natural Science Foundation of China (51579089).

\section{References}

[1] J. Lian, H. Wang, and H. Wang, "Study on vibration transmission among units in underground powerhouse of a hydropower station," Energies, vol. 11, no. 11, p. 3015, 2018.

[2] J. Zhang, F. Yang, C. Liang, Y. Zhang, and Y. Li, “An SVDDbased post-processing approach for vibration risk assessment of the hydro-turbine-generator in a large hydropower station," Journal of Low Frequency Noise, Vibration and Active Control, vol. 40, no. 3, pp. 1309-1334, 2020.

[3] R. K. Mohanta, T. R. Chelliah, S. Allamsetty, A. Akula, and R. Ghosh, "Sources of vibration and their treatment in hydro power stations-a review," Engineering Science and Technology, An International Journal, vol. 20, no. 2, pp. 637-648, 2017.

[4] S. Dyke and B. Spencer, "A comparison of semi-active control strategies for the MR damper," in Proceedings of the Intelligent Information Systems-IIS'97, pp. 580-584, IEEE, Grand Bahama Island, Bahamas, December 1997. 
[5] N. Mohajer Rahbari, B. Farahmand Azar, S. Talatahari, and H. Safari, "Semi-active direct control method for seismic alleviation of structures using MR dampers," Structural Control and Health Monitoring, vol. 20, no. 6, pp. 1021-1042, 2013.

[6] S. Zahrai and H. Salehi, "Semi-active seismic control of midrise structures using magneto-rheological dampers and two proposed improving mechanisms," Iranian Journal of Science and Technology: Transactions of Civil Engineering, vol. 38, no. C1, p. 21, 2014.

[7] S.-Y. Ok, D.-S. Kim, K.-S. Park, and H.-M. Koh, "Semi-active fuzzy control of cable-stayed bridges using magneto-rheological dampers," Engineering Structures, vol. 29, no. 5, pp. 776-788, 2007.

[8] V. Bhaiya, S. Bharti, M. Shrimali, and T. Datta, "Genetic algorithm based optimum semi-active control of building frames using limited number of magneto-rheological dampers and sensors," Journal of Dynamic Systems, Measurement, and Control, vol. 140, no. 10, 2018.

[9] M. Abdeddaim, A. Ounis, N. Djedoui, and M. K. Shrimali, "Pounding hazard mitigation between adjacent planar buildings using coupling strategy," Journal of Civil Structural Health Monitoring, vol. 6, no. 3, pp. 603-617, 2016.

[10] X. J. Qi, X. J. Li, and J. H. Xiao, "Algorithm comparison and analysis of bridge seismic semi-active control," Journal of Vibration and Shock, vol. 25, no. 6, pp. 71-75, 2006.

[11] J. T. P. Yao, "Concept of structural control," Journal of the Structural Division, vol. 98, no. 7, pp. 1567-1574, 1972.

[12] W. Zheng, H. Wang, J. Li, and H. Shen, "Parametric study of superelastic-sliding LRB system for seismic response control of continuous bridges," Journal of Bridge Engineering, vol. 25, no. 9, Article ID 04020062, 2020.

[13] B. Wang, S. Zhu, and F. Casciati, "Experimental study of novel-centering esismic base isolators incorporating superelastic shape memory alloys," Journal of Structural Engineering, vol. 146, no. 7, 2020.

[14] S. Gur, G. N. Frantziskonis, and S. K. Mishra, "Thermally modulated shape memory alloy friction pendulum (tmSMAFP) for substantial near-fault earthquake structure protection," Structural Control and Health Monitoring, vol. 24, no. 11, 2017.

[15] Y. Peng, T. Huang, and J. Chen, "Experimental study of seismic isolated structures with sliding implant-magnetic bearings," Journal of Earthquake Engineering, pp. 1-32, 2020.

[16] Y. Peng, L. Ding, J. Chen, and R. Villaverde, "Experimental study of sliding hydromagnetic isolators for seismic protection," Journal of Structural Engineering, vol. 145, no. 5, Article ID 04019021, 2019.

[17] P. W. Nugroho, W. Li, H. Du, G. Alici, and J. Yang, "An adaptive neuro fuzzy hybrid control strategy for a semiactive suspension with magneto rheological damper," Advances in Mechanical Engineering, vol. 6, Article ID 487312, 2014.

[18] P. J. Gawthrop, S. A. Neild, and D. J. Wagg, "Semi-active damping using a hybrid control approach," Journal of Intelligent Material Systems and Structures, vol. 23, no. 18, pp. 2103-2116, 2012.

[19] M. Ahmadian and N. Vahdati, "Transient dynamics of semiactive suspensions with hybrid control," Journal of Intelligent Material Systems and Structures, vol. 17, no. 2, pp. 145-153, 2006.

[20] M. Bitaraf, O. E. Ozbulut, S. Hurlebaus, and L. Barroso, "Application of semi-active control strategies for seismic protection of buildings with MR dampers," Engineering Structures, vol. 32, no. 10, pp. 3040-3047, 2010.
[21] Z. G. Ying, W. Q. Zhu, and T. T. Soong, "A stochastic optimal semi-active control strategy for ER/MR dampers," Journal of Sound and Vibration, vol. 259, no. 1, pp. 45-62, 2003.

[22] R. Alkhatib and M. F. Golnaraghi, "Active structural vibration control: a review," The Shock and Vibration Digest, vol. 35, no. 5, pp. 367-383, 2003.

[23] A. Bathaei, S. M. Zahrai, and M. Ramezani, "Semi-active seismic control of an 11-DOF building model with TMD+MR damper using type-1 and -2 fuzzy algorithms," Journal of Vibration and Control, vol. 24, no. 13, pp. 2938-2953, 2018.

[24] H. J. Lee, G. Yang, H. J. Jung, B. F. Spencer, and I. W. Lee, "Semi-active neurocontrol of a base-isolated benchmark structure," Structural Control and Health Monitoring: The Official Journal of the International Association for Structural Control and Monitoring and of the European Association for the Control of Structures, vol. 13, no. 2-3, pp. 682-692, 2006.

[25] N. K. Hazaveh, J. G. Chase, G. W. Rodgers, and S. Pampanin, "Smart semi-active MR damper to control the structural response," Bulletin of the New Zealand Society for Earthquake Engineering, vol. 48, no. 4, pp. 235-244, 2015.

[26] D.-H. Kim and I.-W. Lee, "Neuro-control of seismically excited steel structure through sensitivity evaluation scheme," Earthquake Engineering \& Structural Dynamics, vol. 30, no. 9, pp. 1361-1377, 2001.

[27] J. Chen, J. Jiang, K. Wang, and F. Zhang, "Optimal placement of actuators for active vibration control using EER and genetic algorithm," in Proceedings of the 2019 IEEE 10th International Conference on Mechanical and Aerospace Engineering (ICMAE), pp. 449-453, IEEE, Brussels, Belgium, July 2019.

[28] M. P. Singh and L. M. Moreschi, "Optimal placement of dampers for passive response control," Earthquake Engineering \& Structural Dynamics, vol. 31, no. 4, pp. 955-976, 2002.

[29] F. Amini and P. Ghaderi, "Optimal locations for MR dampers in civil structures using improved ant colony algorithm," Optimal Control Applications and Methods, vol. 33, no. 2, pp. 232-248, 2012.

[30] G. Agranovich and Y. Ribakov, "A method for efficient placement of active dampers in seismically excited structures," Structural Control and Health Monitoring, vol. 17, no. 5, pp. 513-531, 2010.

[31] J. A. Main and S. Krenk, "Efficiency and tuning of viscous dampers on discrete systems," Journal of Sound and Vibration, vol. 286, no. 1-2, pp. 97-122, 2005.

[32] R. Lewandowski, "Optimization of the location and damping constants of viscous dampers," in Proceedings of the Ninth International Conference on Computational Structures Technology, Athens, Greece, September 2008.

[33] M. P. Singh and L. M. Moreschi, "Optimal seismic response control with dampers," Earthquake Engineering \& Structural Dynamics, vol. 30, no. 4, pp. 553-572, 2001.

[34] J. Zhang and K. Zhang, "Improved multi-objective sensor optimization method for structural damage identification based on genetic algorithm," IOP Conference Series: Materials Science and Engineering, vol. 780, no. 3, Article ID 032022, 2020.

[35] Y.-K. Wen, "Method for random vibration of hysteretic systems," Journal of the Engineering Mechanics Division, vol. 102, no. 2, pp. 249-263, 1976.

[36] Y. G. Li, M. Chen, H. Y. Long, and L. Y. Ju, "Identifying the parameters of bouc-wen model for MR damper based on matlab," Machine Tool \& Hydraulics, vol. 46, no. 5, pp. 97-101, 2019. 
[37] N. R. Fisco and H. Adeli, "Smart structures: Part I-active and semi-active control," Scientia Iranica, vol. 18, no. 3, pp. 275-284, 2011.

[38] E. Lee, J. Park, K. A. Loparo, C. B. Schrader, and P. H. Chang, "Bang-bang impact control using hybrid impedance/timedelay control," IEEE/ASME transactions on mechatronics, vol. 8, no. 2, pp. 272-277, 2003.

[39] K. B. Saad, A. Mbarek, and M. Benrejeb, "Determination of the switching times of the bang-bang control for a linear stepping motor by Lyapunov functions," Studies in Informatics and Control, vol. 17, no. 4, p. 393, 2008.

[40] U. Ledzewicz and H. Schättler, "Optimal bang-bang controls for a two-compartment model in cancer chemotherapy," Journal of Optimization Theory and Applications, vol. 114, no. 3, pp. 609-637, 2002.

[41] P. Azimzadeh and P. A. Forsyth, "The existence of optimal bang-bang controls for GMxB contracts," SIAM Journal on Financial Mathematics, vol. 6, no. 1, pp. 117-139, 2015.

[42] P. Dong and J. Fan, "Semiactive wind response control of 76story benchmark building with smart piezoelectric friction dampers," in Advanced Materials Research, vol. 250-253, pp. 2196-2201, Trans Tech Publications, Freienbach, Switzerland, 2011.

[43] S.-S. Chen and J.-H. Li, "Analyses of semi-active control of earthquake response to building structure by magneto-rheological damper," Journal of Railway Engineering Society, vol. 9, 2007.

[44] W. Wang, X. Hua, X. Wang, J. Wu, H. Sun, and G. Song, "Mechanical behavior of magnetorheological dampers after long-term operation in a cable vibration control system," Structural Control and Health Monitoring, vol. 26, no. 1, Article ID e2280, 2019.

[45] J. Gené-Badia, G. Escaramis-Babiano, M. Sans-Corrales et al., "Impact of economic incentives on quality of professional life and on end-user satisfaction in primary care," Health Policy, vol. 80 , no. 1, pp. 2-10, 2007.

[46] H. Natke and T. Soong, "Topological structural optimization under dynamic loads," WIT Transactions on The Built Environment, vol. 2, 1970.

[47] Z. Dong, Z. Feng, Y. Chen, K. Yu, and G. Zhang, "Design and multiobjective optimization of magnetorheological damper considering the consistency of magnetic flux density," Shock and Vibration, vol. 2020, Article ID 7050356, 12 pages, 2020.

[48] W. Zhu and X.-T. Rui, "Semiactive vibration control using a magnetorheological damper and a magnetorheological elastomer based on the Bouc-Wen model," Shock and Vibration, vol. 2014, Article ID 405421, 10 pages, 2014.

[49] X. Zhang, Z. Li, K. Guo, F. Zheng, and Z. Wang, "A novel pumping magnetorheological damper: design, optimization, and evaluation," Journal of Intelligent Material Systems and Structures, vol. 28, no. 17, pp. 2339-2348, 2017.

[50] S. Kanarachos, D. Savitski, N. Lagaros, and M. E. Fitzpatrick, "Automotive magnetorheological dampers: modelling and parameter identification using contrast-based fruit fly optimisation," Soft Computing, vol. 22, no. 24, pp. 8131-8149, 2018.

[51] C. Su and Y. Yang, "Study on intelligent vibration control of hydropower powerhouse based on magnetorheological damper," Water Power, vol. 8, pp. 36-41, 2019. 